\title{
COVID-19: vacunas
}

\author{
David Gaus[1]
}

1. University of Wisconsin School of Medicine, Department of Family Medicine and Community Health, EEUU.

Doi: https://doi.org/10.23936/pfr.v6i1.196

PRÁCTICA FAMILIAR RURAL | Vol.6 | No.1 | Marzo 2021 | Recibido: 19/03/2021 | Aprobado:29/03/2021

\section{Cómo citar este artículo}

Gaus, D. COVID-19: vacunas. Práctica Familiar Rural. 2021 marzo; 6(1).

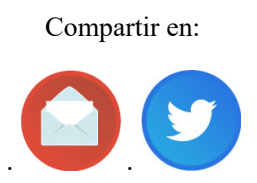

\section{Resumen}

Se realizó una revisión bibliográfica sobre las vacunas contra el Covid-19, exponiendo las plataformas que utilizan, así como los requerimientos para almacenamiento y transporte. Se analiza la inequidad en el acceso a estas vacunas entre los países de altos ingresos, con los países pobres, y al interior de estos últimos. Los países desarrollados han iniciado un proceso agresivo de vacunación en sus poblaciones, olvidando que el éxito o el fracaso de las vacunas dependen de la cantidad de inmunizaciones que se logren en todo el planeta y no solo en algunos territorios.

Palabras clave: vacuna, covid-19, salud global

COVID-19: vaccines

\begin{abstract}
A bibliographic review was carried out on the vaccines against Covid-19, exposing the platforms they use, as well as the requirements for storage and transport. Inequity in access to these vaccines is analyzed between high-income countries, with poor countries, and within the latter. Developed countries have begun an aggressive vaccination process in their populations, forgetting that the success or failure of vaccines depends on the number of immunizations that are achieved throughout the planet and not only in some territories.
\end{abstract}

Keywords: vaccine, covid-19, global health

\section{Introducción}

Se entiende por "plataforma de vacuna" a una categoría de vacuna que se asocia a una tecnología para su producción y a una forma de actuar sobre el sistema inmune. Las plataformas de vacunas hasta ahora desarrolladas son: virus vivos atenuados, virus inactivados o muertos, con vectores virales (replicantes y no replicantes) también llamadas de virus

recombinantes, vacunas basadas en ácidos nucleicos (ADN o ARNm) y vacunas a base de proteínas virales (proteínas completas, subunidades de proteínas, partículas similares a virus, proteínas recombinantes).

En términos generales, las vacunas requieren dos componentes; en primer lugar, antígenos del patógeno-diana que son proporcionados en la vacuna o pueden ser generados por el individuo receptor de la vacuna; y en segundo lugar, una señal de infección (como un patrón molecular asociado a patógenos o un patrón molecular asociado a daño) que alerta y activa el sistema inmunológico del huésped.

A nivel nacional es importante resaltar que se requiere una adecuada vocería para la difusión de información acerca de la vacuna con la finalidad de sensibilizar adecuadamente a la comunidad, sus beneficios, así como de sus efectos adversos. Una encuesta realizada en el Ecuador, demuestra que el $40 \%$ de los encuestados, no están dispuesto a vacunarse, esto ejemplifica la complejidad que deben superar los países latinoamericanos para superar sus limitaciones económicas, culturales y técnicos que limitan el éxito de la vacunación en las poblaciones pobres.

Esta revisión se dedica al tema de vacunas, a pesar de que la disponibilidad masiva de ellas está concentrada principalmente en países de altos ingresos hasta la fecha.

\section{Metodología}

Lectura crítica de la evidencia del desarrollo de las vacunas y el reto que deben enfrentar los países, para lograr una estrategia éxitosa a nivel planetario. 


\section{Vacunas Autorizadas}

\section{Pfizer-BioNTech}

La vacuna tiene una plataforma técnica de "ARN mensajero" (mARN). El mARN genera la producción de la proteína S ("spike protein") del virus COVID-19. La vacuna no contiene el virus y no puede causar infección de COVID-19. Requiere 2 dosis separadas con 21 días como mínimo.

Se tiene que mantener en temperaturas muy frías (cadena del frio) de $-70^{\circ} \mathrm{C}$. Se puede transportar la vacuna en termos especiales que pueden mantener esta temperatura durante 10 días, pero sin abrir el termo. Los termos tienen sensores para monitorizar la temperatura durante los 10 días máximo de transporte. Una vez que llega a su destino, existen tres opciones para la vacuna:(1).

- La vacuna se puede guardar nuevamente en un congelador de $-70^{\circ} \mathrm{C}$ por hasta 6 meses.

- Se puede reutilizar los termos de Pfizer, reemplazando el hielo especial cada 5 días. Esto permite 30 días de almacenamiento seguro.

- La vacuna se puede guardar en una refrigeradora común con temperatura entre $2-8^{\circ} \mathrm{C}$ por hasta 5 días. Una vez en temperaturas de $2-8^{\circ} \mathrm{C}$, ya no se puede volver a congelar sin que se dañe la vacuna.

Cuando la vacuna se extrae de refrigeración para administrar, se mezcla con un diluyente de solución salina. Desde ese momento, la vida útil de la vacuna es hasta 6 horas. Se debe botar a la basura cualquier residuo de la vacuna luego de 6 horas porque ya no tiene eficacia.(2).

\section{Moderna}

La vacuna tiene una plataforma técnica similar a la vacuna de Pfizer-BioNTech y también requiere 2 dosis separadas con 28 dias.(ㄱ). Se tiene que mantener en temperaturas menos frías $\left(-20^{\circ} \mathrm{C}\right)$ que la vacuna de Pfizer. Se puede guardar en refrigeradoras a temperaturas entre $2-8^{\circ} \mathrm{C}\left(36-46^{\circ} \mathrm{F}\right)$ durante hasta 30 días. No requiere mezclarse con ningún diluyente para su administración. Una vez extraída de refrigeración para su administración, la vacuna se puede mantener a temperatura ambiental hasta 12 horas para mantener su eficacia.(4).

\section{AstraZeneca-Oxford}

La vacuna tiene una plataforma técnica que se llama "vector viral", que utiliza un adenovirus (muy diferente a un coronavirus) que induce al ser humano a producir una parte del COVID-19 virus que es la proteína $\mathrm{S}$ (spike protein).(드). Luego la respuesta inmune del paciente produce anticuerpos para atacar esa proteína S si el virus de COVID-19 logra entrar al cuerpo, efectivamente minimizando el riesgo de infección importante en el paciente. Se requiere 2 dosis y la segunda dosis se debe administrar 4-12 semanas luego de la primera. Está terminando la fase III de los ensayos clínicos de la vacuna. Se puede guardar en temperaturas entre $2-8^{\circ} \mathrm{C}$ (mucho menos frías que la vacuna de Pfizer) hasta 6 meses. Para su administración, puede soportar temperaturas hasta $30^{\circ} \mathrm{C}$ por 6 horas. Pasado las 6 horas, se debe botar.

\section{Janssen/Johnson \& Johnson (J\&J)}

La vacuna de J\&J tiene la misma plataforma que la de AstraZeneca-Oxford, que es un vector viral, utilizando un adenovirus que no causa enfermedad para transportar material genético de COVID-19 a su interior y producir una parte del COVID-19 que es la proteína S. La proteína S se expresa en la superficie de las células y el cuerpo humano produce anticuerpos que estarán presentes para atacar y eliminar el COVID-19 virus si hubiera infección.(ㅁ) Se puede guardar entre 2$8^{\circ} \mathrm{C}$. Una vez perforada la ampolla de la vacuna, tiene 6 horas de utilidad. Luego de 6 horas, se debe descartar la ampolla.(7).

\section{Sputnik V}

La vacuna Rusa es otra vacuna con tecnología de vector viral previamente descrito y requiere 2 dosis, la segunda se administra luego de 21 días. La vacuna utiliza 2 diferentes adenovirus como vector, uno es para la primera vacuna, y el otro adenovirus es para el refuerzo. Fue aprobada en agosto 2020 antes que empiecen los ensayos clínicos de fase III, lo que provocó dudas acerca de su eficacia y seguridad en la comunidad científica mundial. Últimamente, con la realización de más estudios, existe más apoyo para la vacuna. Existen dos versiones de la vacuna. Una se debe guardar a $-18^{\circ} \mathrm{C}$. La otra versión es liofilizada (seca) y puede ser guardada entre $2-8^{\circ} \mathrm{C}$

\section{Sinovac (CoronaVac)}

Es una vacuna China que utiliza una tecnología más tradicional, que son partículas inactivadas del virus para exponer el sistema inmune humano al virus sin riesgo de enfermedad grave. Se requiere una segunda dosis 14 días después de la primera. No se ha compartido datos sobre su eficacia públicamente. Aunque sigue en ensayos clínicos de fase III, la empresa está vendiéndola en el mercado y algunos países están aprobándola para su uso. Se puede guardar la vacuna entre $2-8^{\circ} \mathrm{C}$, y soporta temperaturas hasta $25^{\circ} \mathrm{C}$ por 6 semanas.(ㅁ) Por estas características, existen mucha demanda de países de bajos ingresos que la buscan.().

\section{Eficacia de las Vacunas}

La eficacia de las vacunas se refiere a la capacidad de prevenir síntomas, no debe confundirse con la capacidad de prevenir infección. Se reporta la eficacia de las vacunas en tabla 1. Por esto, se recomienda otras medidas de prevención a pesar de ser vacunado porque una persona vacunada aún puede ser contagiosa, pero el riesgo es mínimo.

Tabla 1. Eficacia de varias vacunas en circulación hasta febrero 2021

\section{VACUNA}

Pfizer-BioNTech

Moderna

AstraZeneca-Oxford

Janssen/Johnson \& Johnson

Sputnik V

Sinovac
EFICACIA

95\%_(10).

$96 \%(\underline{11})$

$79 \%(\underline{12})$

$66 \%(\underline{13})$

$92 \%(\underline{14})$

$50-83 \%(\underline{15})$

Existe evidencia sobre el desarrollo de protección significativa luego de una sola dosis en las vacunas de 2 dosis. Las vacunas Pfizer-BioNTech, Moderna, AstraZeneca-Oxford ofrecen protección de infección sintomática de $52 \%, 80 \%, 64 \%$ respectivamente.(16). Esta es la base del argumento de muchas salubristas de 
que los países con acceso limitado a las vacunas, deben enfocar sus esfuerzos en vacunar toda la población por primera vez y preocuparse menos por la segunda dosis inicialmente.

La utilidad de la vacuna en personas con infección previa de COVID-19

La evidencia actual demuestra que la respuesta inmune, luego de una infección asintomática, no es suficiente y no dura mucho tiempo para afirmar que el riesgo de una nueva infección con por SARS-COV sea mínimo.(17) Por ende, utilizar estudios de seroprevalencia para captar la población que tuvo infección con COVID-19 para predecir inmunidad de rebaño tiene poca utilidad. Al mismo tiempo hasta la fecha, no existe evidencia de que un paciente con infección previa y sintomática con COVID-19, al recibir la vacuna, tenga mayor riesgo de efectos secundarios u otras complicaciones. La conclusión es que infección previa no es una contraindicación para la vacuna.

\section{Efectos Secundarios de las vacunas}

Los efectos secundarios de todas las vacunas de COVID-19, hasta la fecha, son comunes pero mínimos (Tabla 2). Entre las vacunas que requieren 2 dosis, la frecuencia de efectos secundarios es mayor. El riesgo de una reacción anafiláctica existe, pero es extremadamente mínimo. En general, el riesgo de efectos secundarios es menor en pacientes mayores a 55 años.

Tabla 2. Efectos secundarios de algunas vacunas de COVID-19

\begin{tabular}{|c|c|c|c|c|c|}
\hline \multirow{2}{*}{$\begin{array}{c}\text { Efecto } \\
\text { Secundario } \\
(\%)\end{array}$} & \multicolumn{2}{|c|}{$\begin{array}{c}\text { Pfizer- } \\
\text { BioNTech* }\end{array}$} & \multicolumn{2}{|c|}{ Moderna } & \multirow[t]{2}{*}{$\begin{array}{c}\text { Johnson \& } \\
\text { Johnson }\end{array}$} \\
\hline & 1era & 2nda & 1era & 2nda & \\
\hline Dolor local & 83 & 78 & 87 & 90 & 59 \\
\hline Fatiga & 47 & 59 & 39 & 68 & 44 \\
\hline Cefalea & 42 & 52 & 35 & 63 & 44 \\
\hline Mialgias & 21 & 37 & 24 & 61 & 39 \\
\hline Escalofríos & 14 & 35 & 9 & 48 & -- \\
\hline Artralgias & 11 & 22 & 17 & 45 & -- \\
\hline Nausea/vomito & 1 & 2 & 9 & 21 & 16 \\
\hline Fiebre & 4 & 16 & 1 & 17 & 13 \\
\hline Adenopatía & -- & & 7 & 16 & -- \\
\hline Edema & 6 & 6 & 7 & 13 & 7 \\
\hline Eritema & 5 & 6 & 3 & 9 & 9 \\
\hline
\end{tabular}
* Los efectos secundarios de la vacuna de Pfizer solo son
de pacientes menores a 55 años.

Fuente: The Guardian, 2021(모)

Con relación a la vacuna de AstraZeneca-Oxford, durante fase III de ensayos clínicos, inicialmente los investigadores reportaron un riesgo de trombosis asociado con la vacuna, pero luego de más análisis, el riesgo de trombosis en pacientes vacunados no fue mayor que trombosis en la población general. Datos específicos sobre efectos secundarios no están disponibles para las vacunas de Sputnik y Sinovac, pero los informes iniciales demuestran que sus efectos secundarios están dentro de los rangos aceptables.(19).

Costo de las Vacunas 
Los precios de las vacunas pueden variar, pero generalmente están entre US\$8 - 25 (Tabla 3).

\section{Tabla 3. Precios de 5 vacunas de COVID-19}

$\begin{array}{lc}\text { Vacuna } & \text { Precio (US\$) } \\ \text { AstraZeneca-Oxford } & 2.16-5.25 \\ \text { Johnson \& Johnson } & 8.50 \\ \text { Sputnik V } & 10 \\ \text { Sinovac } & 13.60(\underline{20}) \\ & \\ \text { Pfizer BioNTech } & 14.50-20 \\ & 18-33\end{array}$

Fuente: RFERL, 2021(21)

\section{Necesidad de Vacunar a Nivel Global}

Hasta el 23 de marzo de 2021, La OMS reportó 398 millones de dosis administrados a nivel mundial, con un promedio de 10.6 millones de dosis diarias.(22) 146 países están reportando estadísticas sobre vacunación. Our World in Data reporta 475 millones de vacunas administradas globalmente.(23). Pero la pregunta es, ¿cómo está la distribución de las vacunas? América del Sur reporta 30 millones, América del Norte 140 millones, Europa 104 millones, Asia 191 millones, y África 8 millones. Esto significa que América del Sur y África, con $25 \%$ de la población mundial, representa tan solo $8 \%$ del total de vacunas, demostrando la tremenda inequidad entre países ricos y países pobres. $(\underline{24})$

Esta situación destaca tres problemas fundamentales:

Si la transmisión comunitaria de COVID-19 persiste en regiones donde las coberturas de vacunación se mantienen bajas, también persiste el riesgo de más mutaciones y variantes del virus. Estas variantes conllevan el riesgo de ser más contagiosas, más virulentas, y más resistentes a las vacunas actuales. En un caso extremo, no es una locura pensar que las vacunas de ahora sean inútiles en poco tiempo.

Volvemos a la misma reflexión de Ferguson en su libro de 1990, "The Anti-Politics Machine" donde el critica los gobiernos y las agencias de desarrollo internacional que toman decisiones completamente políticas sobre la asignación de recursos y las hacen aparecer como "soluciones técnicas para problemas técnicos."(25). La pandemia demuestra que nada ha cambiado.

Finalmente, la asignación de vacunas de COVID-19 destapa otro problema del supuesto de la "salud global." No existe gobernación en salud global. Cada país se preocupa por sus propios intereses. Un estudiante de Salud Pública podría argumentar que ese papel le compete a la OMS. ¿Pero qué poder tiene la OMS? En las 70 s, era otra institución. Hoy en día, es una burocracia que intenta crear políticas de salud global, pero no tiene la capacidad de hacerlas cumplir, y tiene muy poca fuerza política para negociar con los países que la controlan. Su manejo de las vacunas de COVID describe perfectamente los limitantes de la OMS. Su proyecto COVAX recomienda como los países deben repartir las vacunas, pero se nota que no tiene ninguna capacidad de hacer cumplir sus normativas. El $8 \%$ de las vacunas de COVID-19 para 25\% de la población mundial demuestra la incapacidad de la OMS.

Referencias bibliográficas

1. https://www.pfizer.com/news/hot-topics/covid_19 vaccine u_s distribution fact sheet accessed 23 Marzo 2021

2. https://www.cdc.gov/vaccines/covid-19/info-by=product/pfizer/downloads/storage-summary.pdf accessed 23 marzo 2021

3.

https://www.ema.europa.eu/en/medicines/human/EPAR/covid-19-vaccinemoderna\#: : :text=COVID $\% 2$ D $19 \% 20$ Vaccine $\% 20$ Moderna $\% 20$ is, virus $\% 20$ that $\% 20$ causes $\% 20$ COVID $\% 2$ D 19 . Accessed 23 marzo 2021

4. https://www.cdc.gov/vaccines/covid-19/info-by_product/moderna/downloads/storage-summary.pdf accessed 23 marzo 2021

5. https://www.ema.europa.eu/en/documents/product-information/covid-19-vaccine-astrazeneca-epar-product-information_en.pdf accessed 23 marzo 2021

6. https://theconversation.com/how-does-the-johnson-and-johnson-vaccine-compare-to-other-coronavirus-vaccines-4-questions-answered155944\#: :text=The $\% 20$ Johnson $\% 20 \% 26 \% 20$ Johnson $\% 20$ vaccine $\% 20$ is, $\% 2$ DCoV $\% 2$ D2\%20spike $\% 20$ protein. Accessed 23 marzo 2021

7. https://www.cdc.gov/vaccines/covid-19/info-by=product/janssen/downloads/janssen-transportation-guidance.pdf accessed 21 marzo 2021

8. China's Sinovac coronavirus vaccine candidate appears safe, slightly_weaker in elderly]]» Reuters (7 de setiembre de 2020)(en inglés)

9. https://www.usnews.com/news/world/articles/2021-03-31/sinopharm-sinovac-covid-19-vaccine-data-show-efficacy-who accessed 5 abril 2021

10. https://www.bbc.com/future/article/20210114-covid-19-how-effective-is-a-single-vaccine-dose. Accessed 21 marzo 2021

11. https://www.bbc.com/future/article/20210114-covid-19-how-effective-is-a-single-vaccine-dose. Accessed 21 marzo 2021 
12. https://www.sciencemag.org/news/2021/03/astrazeneca-reports-powerful-covid-19-protection-new-vaccine-trial accessed 21 marzo 2021

13. https://www.gavi.org/vaccineswork/everything-we-know-about-johnson-johnsons-single-dose-covid-19-vaccine?gclid=Cj0KCQjwo-aCBhCARIsAAkNQitobAC7BN9PeVPAqOERXYKIWpCgR9fRAPdyhIUGQTj2Z54uYoDznTYaAgoJEALw wcB accessed 21 marzo 2021

14. Baraniuk C. Covid-19: What do we know about Sputnik V and other Russian vaccines? BMJ 2021;372:n743 (publ 19 Marzo 2021).

15. https://www.usnews.com/news/world/articles/2021-03-31/sinopharm-sinovac-covid-19-vaccine-data-show-efficacy-who accessed 5 abril2021

16. https://www.bbc.com/future/article/20210114-covid-19-how-effective-is-a-single-vaccine-dose. Accessed 21 marzo 2021

17. He Z, Ren L, Yang J, et al. Wuhan, China: a longitudinal, population-level, cross-sectional study. Lancet. 2021. 397(10279);March 20-26:1075-84

18. https://www.theguardian.com/world/2021/mar/18/covid-vaccine-side-effects-pfizer-moderna-johnson-is-it-safe. Revisado 22 marzo 2021

19. https://www.globaltimes.cn/page/202103/1217762.shtml accessed 5 abril 2021

20. https://www.bbc.com/news/world-asia-china-55212787 accessed 5 abril2021

21. https://www.rferl.org/a/sputnik-v-vaccine/31133608.html Revisado 24 marzo 2021

22. https://mail.google.com/mail/u/0/\#search/hpkins/FMfcgxwLtGhBDMlkgscGxvfQrDRZMmpj accessed 24 marzo 2021

23. https://ourworldindata.org/explorers/coronavirus-data-explorer?zoomToSelection=true\&time=2020-03$\underline{01 . \text { latest } \& \text { country }=\& \text { region }=\text { World } \& \text { pickerMetric }=\text { total cases } \& \text { pickerSort }=\text { desc } \& \text { tab }=\text { table } \& \text { Metric }=\text { Vaccinations } \& I n t e r v a l=C u m u l a t i v e ~} \& A$ lign + outbreaks $=$ false $\& R$ accessed 24 marzo 2021

24. https://www.prb.org/2020-world-population-data-sheet $/ \#: \sim:$ text $=$ The $\% 20$ world $\% 20$ population $\% 20$ is $\% 20$ projected, as $\% 20$ in $\% 20$ the $\% 20$ United $\% 20$ States. Accessed 24 marzo 2021

25. Ferguson, James (1990). The Anti-Politics Machine: "Development," Depoliticization and Bureaucratic Power in Lesotho. Cambridge: Cambridge University Press. 